\title{
Peranan Wan Akub di Muntok Bangka Abad ke-18
}

\author{
Yuliarni \\ Program Studi Pendidikan Sejarah, Fakultas Keguruan dan Ilmu Pendidikan, \\ Universitas Muhamadiyah Palembang \\ Jl. Jendral Ahmad Yani, Kelurahan 13 Ulu, Kecamatan Plaju, Palembang, Indonesia \\ "Alamat korespondensi: yuliarnierie1@gmail.com \\ DOI: https://doi.org/10.14710/jscl.v5i2.29739
}

Diterima/Received: 25 April 2020; Direvisi/ Revised: 1 Januari 2021; Disetujui/Accepted: 1 Januari 2021

\begin{abstract}
The development of Muntok could not be separated from the long historical story of its original name. This research is presented the background of Wan Akub's arrival in Muntok and his role in the government and economy in the 18th century. This study uses historical methods emphasizes on the biographical approach. Wan Akub is the head of government in Muntok who was sent by the Palembang Sultanate as well as the head of tin mining. Some of his policies were to open an irrigation system or help the tin mining process in Muntok as economic resources for the locals. There were various policies that had been made a considerable influence in Muntok. He imported tin miners from Johor and built clay fortresses to reduce ethnic disputes in Muntok as well introduced tin tiban regulations. He also initiated the distribution of tin products as a form of remuneration. In addition, the migration of Wan Akub's relatives from Siantan left for Bangka acquired by new skills in cloth weaving technique called Cual.
\end{abstract}

Keywords: Wan Akub; Muntok; Malay Figure; Palembang Sultanate.

\begin{abstract}
Abstrak
Kemajuan Kota Muntok tidak dapat terlepas dari cerita sejarah panjang dari asal usul nama Muntok itu sendiri. Penelitian ini dihadirkan dengan tujuan untuk mengetahui latar belakang kedatangan Wan Akub sebagai tokoh Melayu berpengaruh di Muntok serta perannya di Muntok pada abad ke-18. Penelitian ini menggunakan metode penelitian sejarah atau historis. Pendekatan yang digunakan dalam penelitian ini adalah pendekatan politik, ekonomi, budaya dan sosiologi. Wan Akub merupakan kepala pemerintahan di Muntok yang diutus oleh Kesultanan Palembang sekaligus kepala pertambangan timah. Berbagai kebijakan yang telah dibuat menyebabkan pengaruh yang cukup besar bagi Kota Muntok menjadi lebih maju. Beberapa kebijakannya adalah membuka sistem irigasi atau parit untuk membantu proses penambangan timah di Muntok, mendatangkan penambang timah dari luar Muntok atau berasal dari Johor, membangun benteng tanah liat untuk meredam pertikaian antar etnis di Muntok, menghadirkan peraturan timah tiban, dan menetapkan pembagian hasil timah sebagai bentuk balas jasa kepada Wan Akub dan kerabatnya. Selain itu, perpindahan kerabat Wan Akub dari Siantan meninggalkan keterampilan baru bagi masyarakat Bangka Muntok mengenai teknik menenun kain yang disebut Cual.
\end{abstract}

Kata Kunci: Wan Akub; Muntok; Tokoh Melayu; Kesultanan Palembang.

\section{Pendahuluan}

Pulau Bangka dikenal sebagai salah satu daerah di Indonesia yang menyimpan banyak cerita dan peninggalan sejarah. Pulau Bangka pada masanya juga sangat dikenal karena perekonomiannya yang maju. Timah dan lada telah membuat pulau kecil ini dikenal hingga mancanegara. Dalam beberapa catatan sejarah disebutkan bahwa Pulau Bangka adalah South East Asia Tin Belt [jalur timah Asia
Tenggara] (Theo, 2014, p. 9). Istilah itu muncul karena interaksi kekuatan imperialis dan kolonialis industri pertambangan timah negara Eropa khususnya Inggris yang terjadi di semenanjung Malaysia dan Bangka (van Wyhe \& Drawhorn, 2015, p. 14; see also Derks, 2012). Ada benang merah yang cukup luas dari interaksi tersebut. Inggris memanfaatkan sumber daya alam yang ada di negera tropis dengan pengenalan industri pengelolaan timah. Industri ini menjadi perluasan 
penambangan timah di daerah Asia Tenggara (Ross, 2014, p. 461).

Ketenaran Pulau Bangka pada akhirnya menyebabkan banyak orang asing tertarik untuk datang. Dalam sejarah pertimahan Bangka tercatat bahwa para pekerja tambang sebagian didatangkan dari Tiongkok. Oleh sebab itu, tidak heran jika hingga saat ini Pulau Bangka masih dihuni oleh banyak keturunan Tionghoa. Mereka bahkan memiliki peranan yang signifikan di kancah politik, ekonomi, dan budaya di pulau Bangka. Banyak di antara mereka menduduki posisi penting di partai politik, bahkan terpilih dan menjabat sebagai kepala daerah (Yuliarni, 2015, p. 2). Selain itu, masyarakat Tionghoa juga mengusai perekonomian di Pulau Bangka. Jika dulu orangorang Tionghoa datang untuk menjadi pekerja timah, saat ini banyak di antara orang Tionghoa menjadi pengusaha timah. Dengan demikian, pengaruh mereka di bidang politik dan ekonomi saling berkaitan (Yuliarni, 2015, p. 5).

Bidang politik dan ekonomi sebenarnya menunjukkan kedekatan. Keduanya saling mempengaruhi satu sama lain. Mengenai peranan masyarakat Tionghoa juga dipicu oleh kedekatan mereka yang dapat berbaru dengan orang Melayu Bangka. Interaksi sosial yang terjadi antara masyarakat Melayu Bangka dengan orang-orang Tionghoa di Bangka terjalin dengan cukup baik. Hal ini ditunjukkan dengan jargon sangat dikenal di Pulau Bangka yaitu thong ngin fan ngin jit jong yang artinya [Tionghoa dan Melayu sama saja] (Theo, 2014, p. 21). Maksud dari "sama" dalam ungkapan tersebut dapat dimaknai sebagai kesamaan dalam banyak hal. Dilihat dari segi ekonomi misalnya, orang Melayu dan Tionghoa umumnya bekerja di bidang yang sama, mulai dari petani, pedagang kecil, mitra tambang, sampai dengan pengusaha. Pemukiman masyarakat melayu Bangka dengan orang-orang Tionghoa juga berdampingan. Salah satu pemandangan yang menunjukkan kedekatan tersebut ialah bangunan masjid dan kelenteng yang dibangun bersebelahan.

Fenomena ini juga diperkuat dengan pernyataan salah seorang tokoh Tionghoa sekaligus Direktur Utama PT Cakra di Sungailiat Bangka, yaitu Yusman Ngui. Diceritakan bahwa "penindasan" tersebut dirasakan warga Tionghoa pada zaman Orde Baru. Bergitu pula kebebasan bagi warga Tionghoa menjadi sangat terkekang.
Namun demikian, perlakuan tersebut sama sekai tidak dirasakan oleh warga Tionghoa di Bumi Serumpun Sebalai (sebutan untuk Provinsi Bangka Belitung). Kondisi yang terjadi di Pulau Bangka justru sebaliknya. Pulau Bangka telah menjadikan keragaman suku, ras dan etnis sebagai sebuah kekayaaan yang tak ternilai harganya sejak lama. Oleh karena itu, selanjutnya muncul istilah untuk Bangka thong ngin fan ngin jit jong.

Meski demikian, dari segi politik ungkapan Thong Ngin Fan Ngin Jit Jong ini tersinyalir kuat terhadap unsur politis. Makna yang terkandung di dalamnya dapat dikatakan sebagai salah satu ajang untuk mempromosikan kandidat dalam menarik simpati massa. Menyitir dari ungkapan umum yang mengatakan bahwa apapun yang berkenaan dengan politik pasti ujungnya tidak lain adalah "kepentingan". Pada kenyataannya, ungkapan thong ngin fan ngin jit jong banyak disitir untuk menyuarakan isu kebersamaan dalam berbagai kampanye. Tidak hanya untuk politisi Melayu, tetapi juga digunakan oleh politisi Tionghoa.

Semua perkembangan itu tidak terlepas dari sejarah kedatangan orang Tionghoa pada masa lalu yang sengaja didatangkan untuk kepentingan menambang. Sultan Palembang yang berkuasa atas Pulau Bangka sengaja mendatangkan para pekerja dari Tiongkok untuk menambang timah di Pulau Bangka. Kehidupan para pekerja tersebut tentu saja terkait dengan pembukaan lahan-lahan baru untuk aktivitas tambang timah. Sebagaimana tercantum dalam sebuah sumber, sebagai berikut:

Sultan Palembang menunjuk seorang peranakan Tionghoa Palembang yakni Cung Huyut (Bong Hu But) untuk mendatangkan kuli timah dari Tiongkok. Para pekerja timah Tionghoa yang lantas disebut dengan istilah singkek itu awalnya ditempatkan di Mentok, Belinyu dan Bunut. Kebanyakan dari mereka berasal dari Tiongkok Selatan terutama dari suku Hakka atau lebih dikenal dengan nama suku Khek. Mereka datang dari Guang Dong yang waktu itu termasuk Kawasan yang tandus dan miskin di Tiongkok. Mereka yang datang kebanyakan seorang bujangan dan petani yang mengadu nasib karena kondisi yang sulit di Tiongkok (Theo, 2014, pp. 11-12).

Teknik penambangan timah di Bangka bahkan diperkenalkan oleh orang Tionghoa. Selain itu, ketokohan keturunan Tionghoa di beberapa 
daerah di Pulau Bangka juga memberikan dampak bagi kemajuan, salah satunya di Kota Muntok. Muntok memiliki posisi geografis yang cukup strategis dalam jalur perdagangan. Muntok sendiri merupakan tempat yang kaya akan kandungan timah, sehingga dianggap sebagai kota penting pada masanya (Ellisa, 2013).

Pada abad ke-18, perkembangan Muntok cukup signifikan. Perkembangan ini tidak lain disebabkan oleh perkembangan penambangan timah yang merupakan produk dari kebijakan pemerintah setempat. Perkembangan kebijakan di Muntok pada Abad ke-18 sangat identik dengan faktor ketokohan Wan Akub (Siburian \& Haba, 2016, p. 225). Oleh sebab itu, mengungkap peranan Wan Akub di Muntok pada Abad ke-18 menjadi sebuah tulisan adalah keniscayaan, mengingat peranannya yang signifikan. Kajian ini bertujuan untuk menjelaskan peranan Wan Akub dalam membangun Muntok pada Abad ke-18.

Wan Akub adalah anak dari seorang bangsawan yang merupakan pemimpin di daerah Siantan bernama Abdulhayat atau bergelar lengkap Ence Wan Abdulhayat. Ibunya juga merupakan anak dari seorang bangsawan Melayu di Johor. Wan Akub berasal dari keluarga muslim Tionghoa yang cukup dikenal oleh masyarakat Muntok. Kedatangan Wan Akub di Muntok pada akhirnya mampu membawa pengaruh yang besar bagi perkembangan Muntok. Berdasar pada hal tersebut, permasalahan yang dikaji dalam penelitian ini adalah ketokohan Wan Akub di tanah Muntok. Terutama mengenai peranannya dalam upaya membangun dan membawa kemajuan bagi Muntok (Ibrahim, 2007, p. 16).

Berdasar pada kajian pendahulu diketahui bahwa beberapa pakar mengakui eksistensi Wan Akub. Ross (2014) dalam kajiannya yang berjudul "The Tin Frontier: Mining, Empire, and Environment in Southeast Asia, 1870s-1930s," mengungkapkan bahwa dalam memahami persoalan penambangan timah di Muntok, Bangka, perlu ditinjau juga mengenai peranan dan interaksi sosial di kalangan masyarakat Melayu-Tionghoa. Apalagi Muntok telah dikenal sebagai penghasil timah pada abad ke 19. Jikalau pun kajian ini belum berhasil menguraikan detail kondisi sosial masyarakat Muntok pada masa pramodern, tetapi dasar bahwa pengembangan ekonomi Muntok terletak pada interaksi antara kekuatan imperialiskolonialis dengan pribumi Melayu-Tionghoa.

Studi Novita (2017) dalam hal ini juga penting untuk dijadikan rujukan. Kajian ini telah menyebut beberapa pemukiman Melayu Kuno di Muntok dan melakukan studi toponimi atas namanama kampung di sana. Hal ini penting untuk melihat seberapa besar peranan orang Melayu dalam menggerakkan sektor perekonomian di Muntok, Bangka. Studi tersebut juga telah menyebut bahwa Wan Akub bin Wan Awang sebagai Kepala Penambangan Timah di Bangka. Argumentasi yang telah dibangun oleh Novita (2017) juga didukung oleh Kurniawan et al. (2018). Kajian ini menunjukkan peranan Wan Akub dalam pengembangan usaha timah di Muntok dan Pulau Bangka secara umum. Dalam analisisnya, dijelaskan bahwa untuk keperluan perluasan penambangan timah, Wan Akub meminta kepada Sultan untuk mengirimkan lebih banyak tenaga kerja yang akan diminta membuat parit timah, mereka adalah orang Melayu dan penduduk Mento'.

Berdasar pada studi-studi yang telah ada tersebut, kajian ini mengidentifikasi pemikiran dari seorang tokoh Melayu-Cina di Muntok yang bernama Wan Akub. Untuk menganalisis peranan tersebut, kajian ini menggunakan metode sejarah dengan juga menekankan pada biografi tokoh. Metode sejarah diartikan sebagai proses menguji dan menganalisis rekaman dan peninggalan masa lampau secara kritis (Gottschalk, 2008, p. 39). Metode sejarah disebut juga sebagai penyelidikan terhadap suatu masalah dengan mengaplikasikan perspektif historis sebagai jalan pemecahannya (Abdurrahman, 2010, p. 53). Dengan demikian, metode sejarah adalah suatu cara yang digunakan untuk menganalisis kejadian masa lampau dengan cara yang ilmiah.

Adapun langkah metode sejarah dimulai dengan heuristik (pengumpulan sumber), kritik sumber, interpretasi, dan historiografi. Teknik heuristik dilakukan melalui penelusuran sumber primer dan sekunder yang relevan. Sumber itu kemudian dianalisis dengan mengritiknya berdasar pada kredibilitasnya. Dalam penelitian ini, digunakan pula beberapa pendekatan lain, yaitu pendekatan politik, ekonomi, budaya, dan sosiologi. 


\section{Latar Belakang Kedatangan Wan Akub di Muntok}

Pada akhir abad ke-17 hingga awal abad ke-18, terjadi pemberontakan di Cina Selatan. Pemberontakan terjadi antara para petani di wilayah Siang Tang melawan Raja Huang Taiji dari Dinasti Qing. Salah seorang pemimpin pemberontakan tersebut adalah hulubalang atau menteri besar dari dinasti itu sendiri, bernama Lim Tau Kian (Sujitno, 2011, p. 126). Pemberontakan tersebut ternyata dapat diatasi oleh pasukan dari Dinasti Qing. Akibatnya, Lim Tau Kian beserta para kerabat dan keluarganya harus pergi meninggalkan Cina. Mereka singgah di Kepulauan Anambas Natuna yang saat itu belum berpenghuni (Kurniawan, et al., 2017, p. 118).

Pulau kosong yang ditempati oleh Lim Tau Kian termasuk dalam wilayah Johor. Menyadari hal tersebut, Lim Tau Kian berusaha menarik perhatian Sultan Johor dengan cara memeluk Islam. Sejak memeluk Islam, Lim Tau Kian mengganti Namanya menjadi Abdulhayat. Pulau tempat Lim Tau Kian menetap kemudian diberi nama Siantan. Diceritakan bahwa Siantan berasal dari kata Siang Tan yang merupakan wilayah asal mereka di Cina Selatan (Sari, 2015, p. 123).

Abdulhayat kemudian menikah dengan wanita Melayu yang merupakan anak dari bangsawan Melayu bernama Wan Awang. Wan Awang adalah putra dari Datuk Engku Laksamana Johor. Oleh karena menikah dengna keluarga bangsawan, Lim Tau Kian juga menjadi bangsawan dengan gelar lengkap "Ence Wan Abdulhayat" dan ditetapkan sebagai Kepala Negeri Siantan. Dari pernikahannya, Abdulhayat dikaruniai tiga orang putra yang ia beri nama Wan Akub, Wan Awang, dan Wan Sirin. Selain menikah dengan wanita keturunan Melayu, Abdulhayat juga menikah dengan gadis Cina dari Dinasti Ming Bowan dan dikaruniai lima putra bernama Abdul Jabar, Abdul Khalik, Zainal Abidin, Abdul Ghani, dan Ismail. Dengan demikian, Siantan telah menjadi daerah tempat tumbuh kembang kerabat dan para keturunan Abdulhayat.

Sementara Abdulhayat memimpin Siantan, di Kesultanan Palembang terjadi pertikaian. Akibat dari pertikaian itu, salah seorang pangeran dari Kesultanan Palembang pergi ke Siantan. Pertikaian yang terjadi di Kesultanan Palembang terjadi tidak lain adalah karena perebutan kekuasaan. Pada mulanya, Kesultanan Palembang dipimpin oleh Sultan Abdurrachman. Sultan Abdurrahman mempunyai dua putra bernama Muhammad Mansyur dan Anom Kamaruddin. Setelah Sultan Abdurrachman wafat, tahta kesultanan jatuh kepada putra pertamanya, yaitu Muhammad Mansyur. Sultan Muhammad Mansyur berkuasa pada 1703 sampai dengan 1714. Ia mempunyai putra yang bernama Pangeran Jayawikrama (Sultan Mahmud Badaruddin I) dari hasil pernikahannya dengan Nyai Mas Senguk atau di Muntok dikenal dengan nama Nek Nguk. Nyai Mas Senguk adalah cucu dari Panembahan Kota Baru Jambi (Isa, t. t., p. 9; Hanafiah, 2009, p. 16).

Pada 1714, Sultan Muhammad Mansyur sakit dan tidak lama kemudian wafat. Ketika ajalnya sudah dekat, ia berwasiat kepada saudaranya Anom Komarudin Sri Truno, dengan disaksikan para pejabat pemerintahan bahwa apabila dirinya wafat, tahta kerajaan harus diserahkan kepada Pangeran Jayawikrama. Namun demikian, yang terjadi setelah Muhammad Mansyur wafat tidak sesuai dengan apa yang diwasiatkan. Anom Komarudin justru menobatkan dirinya sebagai Sultan Palembang dengan gelar Sultan Agung Komarudin Sri Truno. Peristiwa itu telah menimbulkan perpecahan dalam Kesultanan Palembang. Sadar akan timbulnya perang saudara di kesultanan, Pangeran Jayawikrama beserta pengikut setianya berlayar ke Pulau Bangka untuk menghindar. Ia mendarat di Bangka dan justru mendapatkan kepercayaan dari rakyat Bangka. Kepercayaan itu datang karena ia telah membantu menyembuhkan penyakit cacar yang pada waktu itu melanda masyarakat Bangka. Setelah singgah di Bangka selama beberapa saat, rombangan Pangeran Jayawikrama berangkat menuju Johor.

Kedatangan rombongan Pangeran Jayawikrama di Johor diterima dengan baik untuk waktu lama. Walaupun telah hidup dengan tenteram di Johor, namun keinginan untuk mendapatkan kembali tahta di Kesultanan Palembang masih ada. Ia kemudian meminta bantuan kepada Raja Johor. Permintaannya ternyata ditolah oleh Raja Johor secara halus. Selama Pangeran Jayawikrama menetap di Johor, banyak di antara bangsawan istana yang tidak senang. Mereka berupaya untuk mengusir Pangeran Jayawikrama beserta pengikutnya keluar 
dari tanah Johor. Mereka kemudian diusir secara halus oleh Sri Sultan Johor. Setelah keluar dari tanah Johor, Pangeran Jayawikrama beserta rombongan berlayar ke Siantan.

Kedatangan rombongan Pangeran Jayawikrama diterima dengan baik oleh kepala Negeri Siantan yang tidak lain adalah Wan Akub bin Wan Awang. Pangeran Jayawikrama menikah dengan seorang gadis bernama Zamnah di Siantan. Zamnah adalah putri Wan Abdul Jabar yang oleh masyarakat Muntok lebih dikenal sebagai Datuk Muda Dalam (Ellisa, 2013, p. 3; Dediarman, 2019). Ikatan pernikahan antara Pangeran Jayawikrama dan Zamnah secara tidak langsung telah mengaitkan Ence Wan Abdulhayat dengan Kesultanan Palembang.

Setelah menikah dengan Zamnah, Pangeran Jayawikrama bermukim di Siantan. Namun demikian, ia ternyata masih berfikir untuk kembali ke Palembang. Ia ingin mengambil hak sebagai pewaris tahta dari pamannya. Sebelum melakukan penyerangan ke Palembang, Pangeran Jayawikrama bermusyawarah dengan para petinggi di Siantan. Salah seorang di antaranya adalah Wan Akub. Pangeran Jayawikrama menjanjikan kepada kepala-kepala Panglima Siantan bahwa apabila penyerangan berhasil, mereka akan diberi hadiah berupa sebagian tanah Bangka. Wan Akub menyutui usulan itu dan bersedia untuk membantu Pangeran Jayawikrama. Adapun kepala pasukan yang dipilih adalah Daeng Parani, seorang panglima keturunan Melayu dan Bugis. Wan Akub sendiri yang mencari Daeng Parani (Isa, t. t., p. 13).

Atas persetujuan Sultan Johor, Pangeran Jayawikrama bersama istri dan sanak keluarganya berangkat dari Siantan menuju Pulau Bangka. Mereka bermukim di Muntok. Pangeran Jayawikrama atas desakan istrinya kembali berusaha merebut tahta Kesultanan Palembang. Akhirnya, Jayawikrama berangkat ke Palembang dengan membawa serta pasukan yang telah dibentuk bersama Wan Akub. Selama menjalankan misi di Palembang, Jayawikrama meninggalkan Zamnah dan Abdul Jabar di Muntok.

Kedatangan Jayawikrama disambut oleh Sultan Agung Komarudin Sri Truno dengan mengutus Pangeran Dipa Kesuma. Pertemuan antara Jayawikrama dan Pangeran Dipa Kesuma telah menghasilkan sebuah kesepakatan. Pada kesepakatan itu, Pangeran Jayawikrama diberi kedudukan di Keraton Sungai Tengkuruk Palembang. Pada kesepakatan itu pula terjadi perkawinan politik di antara kedua belah pihak. Pangeran Jayawikrama menikahi putri Sultan Agung Komarudin Sri Truno yang bernama Raden Ayuk Senguk dengan gelar "Ratu Rangdan" atau "Ratu Gading", yang merupakan janda dari Pangeran Aria Kesuma Cengek. Dengan perkawinan politik ini, maka Pangeran Jayawikrama resmi menjadi Sultan Palembang sepenuhnya dengan gelar Sultan Mahmud Badaruddin Jayawikrama.

Sultan Mahmud Badaruddin Jayawikrama pernah berjanji kepada bangsawan Siantan, apabila membantu dan berhasil merebut tahta Kesultanan Palembang dari pamannya, maka mereka diberi hadiah sebagian tanah Bangka. Oleh karena mereka berhasil membantu, maka sesuai dengan janjinya, keluarga Zamnah ditempatkan di Pulau Bangka. Wilayah yang dipilih adalah Muntok. Mereka ditempatkan di Muntok karena letaknya yang berada di tengah-tengah persimpangan jalan antara Palembang dan Siantan. Selain itu, mereka ditempatkan di Muntok juga berdasar pada alasan bahwa Ence Wan Akub dan Wan Abdul Jabar sangat paham mengenai penambangan timah yang telah dikenal di Semenanjung Malaya. Setelah bermukim di Muntok, Ence Wan Akub menjadi orang kepercayaan sultan. Ia ditunjuk untuk memegang kekuasaan di Bangka, terutama mengorganisasi penggalian timah. Sebagai orang kepercayaan sultan, Wan Akub diberi gelar Datok Rangga Setya Agama (Novita, 2017, p. 30; Idi, 2011). Sementara itu, Wan Abdul Jabar Sultan Mahmud Badaruddin I ditugaskan sebagai penghulu atau hakim agama di Muntok (Sari, 2015, p. 123).

Berdasar beberapa penjelasan yang telah disebutkan, dapat dianalisis bahwa Sultan Mahmud Badaruddin Jayawikrama tidak hanya sekadar memberikan wilayah kepada Wan Akub dan keluarganya, tetapi juga mampu membaca keuntungan di masa depan. Peruntungan yang dimaksud ialah mengenai pengembangan pertambangan timah. Sultan sangat paham bahwa Wan Akub telah menguasai teknik serta cara mengelola pertambangan timah. Meskipun bukan 
orang asli Muntok, namun Wan Akub tetap menjalankan tugas dengan penuh tanggung jawab.

\section{Beberapa Kebijakan Strategis Wan Akub dalam Sektor Pemerintahan di Muntok}

Wan Akub memegang peranan penting dalam pengambilan kebijakan di Muntok. Pada awalnya, Wan Akub membangun parit-parit untuk kegiatan pertambangan timah di Muntok. Pembukaan parit ini diadaptasi dari sistem penambangan di Johor (Lie \& Theo, 2014, p. 10). Guna mendukung pekerjaan penambangan di Muntok, Wan Akub mendatangkan penambang timah dari Cina, Kamboja, dan Siantan. Sebagian dari mereka telah bekerja di Johor (Lie \& Theo, 2014, p. 11).

Demi menghindari pertikaian antara pekerja dari Tionghoa dan Melayu, Wan Akub membangun benteng dari tanah liat (Sjitno, 2011, p. 148). Ia juga memberlakukan peraturan timah tiban. Peraturan ini bernbunyi "setiap tahun seorang laki-laki yang sudah menikah akan diberi satu potong kain cuki/hitam dan harus memberikan sepotong timah yang beratnya 50 kati” (Sujitno, 2011, p. 146). Kebijakan ini diambil sebagai bentuk pembayaran pajak kepada Sultan Palembang. Selain menetapkan peraturan timah tiban, ada pula kebijakan yang berisi kewajiban bagi pekerja Melayu untuk menyerahkan hasil tambang kepada keluarga Wan Akub (Sujitno, 2011, p. 146). Meskipun demikian, Wan Akub tetap membagikan hasil tambang secara adil. Kebijakan ini disetujui oleh Sultan Palembang sebagai bentuk balas jasa karena Wan Akub dan keluarganya telah mengajarkan teknik pertambangan yang baru di Muntok.

\section{Wan Akub sebagai Tokoh Berpengaruh dalam Pengembangan Usaha Timah Rakyat di Muntok}

Pemberian wewenang kepada Wan Akub oleh Sulta Palembang disebut-sebut sebagai hari jadi Muntok. Wewenang itu secara resmi diserahkan pada 7 September 1734, ditandai dengan pembangunan tujuh bubung rumah di daratan sebuah tanjung yang terletak di kaki menumbing (nama sebuah bukit di Muntok) (Yusuf, 2013). Penyerahan wewenang itu kemudian disebut sebagai hari jadi Muntok, meskipun sebenarnya di di Muntok sudah terbentuk komunitas masyarakat.
Keberadaan Wan Akub menjadi kuat di tanah Muntok karena wewenang yang diberikan oleh Sultan Mahmud Badaruddin Jayawikrama. Melalui wewenang tersebut, Wan Akub membuka peluang satu per satu untuk memajukan tanah Muntok, terutama dalam bidang pertambangan timah. Sebelum Wan Akub datang, Muntok yang saat itu menjadi kota terpenting di Pulau Bangka merupakan daerah yang sebagian di pimpin oleh orang-orang Melayu. Mereka berasal dari Siantan, sehingga sering kali disebut sebagai wilayah kekuasaan orang-orang Siantan. Sultan Mahmud Badaruddin kemudian bertitah agar keluarga Wan Akub agar menetap dan memimpin Muntok untuk waktu yang cukup lama.

Selain membawa serta keluarganya, Wan Akub juga memperkenalkan keterampilan menenun kain yang disebut "cual". Keterampilan itu telah dikembangkan di Siantan. Dengan demikian, selain di bidang pertambangan, Wan Kub dan kerabatnya juga memperkenalkan keterampilan baru di Muntok (Departemen Kebudayaan dan Pariwisata, 2009, p. 12)

Kehadiran Wan Akub beserta kerabatnya harus diakui telah menjadikan Muntok lebih maju dari sebelumnya. Muntok tidak hanya dibangun menjadi lebih baik, tetapi juga ditetapkan sebagai pusat pemerintahan. Sebagai kepala pemerintahan sekaligus yang ditugaskan untuk mengorganisasi penggalian timah di Muntok, Wan Akub menerapkan beberapa kebijakan yang strategis. Hal itu dilakukan salah satunya adalah untuk mengurangi atau meminimaslisasi tindakan monopoli yang dilakukan oleh Vereenigde Oostindische Compagnie(VOC).

Berdasar pada sumber yang didapatkan, diketahui bahwa Wan Akub adalah orang yang kali pertama memperkenalkan teknik menambang timah di Muntok dengan sistem kolong seperti yang diterapkan di Johor (Theo, 2014, p. 10). Pernyataan ini cukup relevan karena teknik penambangan timah sebenarnya sudah dikenal oleh masyarakat Siantan di Semenanjung Malaysia dan Bangka (Ross, 2014, p. 458). Sementara itu, Wan Akub telah lama tinggal di Siantan.

Cara menambang timah yang paling sederhana adalah mendulang sungai dengan piring kayu besar. Selain itu, cara yang lebih umum adalah dengan membuat lampan, atau pintu air tanah. Pada tahap awal, tanah yang akan ditambang harus 
dibersihkan. Tahap selanjutnya adalah menggali saluran dari sungai terdekat untuk mengalihkan air melalui parit dan kemudian mengolah karang saluran. Saat sedimen tanah yang ringan terbawa arus, pasir timah yang berat tertahan oleh serangkaian bendungan kecil. Teknik ini membuat timah dapat cepat diambil dan terkonsentrasi di kotak air (palong).

Kedua metode tersebut telah terbukti sangat menguntungkan, terutama di lahan tambang timah yang sama sekali belum dijamah. Namun demikian, dua teknik ini tetap memiliki kekurangan, yaitu tidak dapat menyaring bijih timah dengan kedalaman tertentu. Apalagi, jika letak timah berada di atas batuan dasar. Untuk mencapai endapan yang dalam, penambang harus menggali lubang terbuka (lombong) beberapa meter. Mereka biasanya naik ke bukit agar dapat membersihkan diri di saluran air.

Semua teknik itu dilaksanakan dalam pengawasan yang ketat. Panning dan ground sluicing hanya dapat dilakukan di lereng yang dekat dengan sungai. Sementara itu, lombong hampir tidak dapat turun di bawah permukaan air tanah dan juga bergantung pada sungai untuk memusatkan kotoran. Pada dasarnya, timah di Bangka adalah endapan dangkal di sisi kaki bukit. Posisi tersebut memudahkan para penambang untuk memanfaatkan akses air (parit) dalam proses penambangan.

Penggalian timah di Muntok pada dasarnya sudah berjalan, namun masih pada taraf yang sederhana dan belum berkembang. Wan Akub seperti yang telah disinggung pada bahasan sebelumnya dikenal sangat paham mengenai penambangan timah khususnya di Semenanjung Malaya. Ia menerapkan cara-cara yang ada di Semenanjung Malaya untuk diterapkan di Muntok. Mengenai system kolong yang diajarkan oleh Wan Akub dengan menggunakan sekop dan pacul, cara ini dinilai lebih cepat daripada sistem lobang sumuran atau galian sukuran yang hanya menggunakan linggis. Wan Akub menetapkan bahwa orang Bangka menggali dengan caranya sendiri di daerah yang sudah ditentukan. Sementara itu, penggalian dengan sistem kolong dilakukan di dalam Muntok. Pasir timah yang telah ditambang kemudian dilebur menjadi logam timah sebelum dipersembahkan kepada sultan.
Dalam upaya untuk mendapatan hasil tambang yang lebih banyak, Wan Akub meminta persetujuan Sultan Palembang untuk membuka parit-parit yang tidak lain untuk mendukung kegiatan tambang timah. Mengingat alasan yang diajukan oleh Wan Akub masuk akal, permintaan tersebut disetujui oleh Sultan Palembang. Setelah mendapatkan persetujuan dari sultan, Wan Akub meminta bantuan patih, batin dan penduduk lokal untuk membangun parit, sebagaimana dilakukan di Johor.

Pembukaan parit-parit telah menyebabkan kekurangan pekerja untuk menambang timah di Muntok. Dalam kondisi demikian, akhirnya Wan Akub menyarankan kepada sultan agar mendatangkan lebih banyak pekerja. Pekerja yang disarankan oleh Wan Akub ialah pekerja dari Cina, Siam, Kamboja, dan Siantan yang berada di Johor. Setelah usulannya disetujui, Wan Akub mengutus Wan Serin untuk menjalankan misi. Wan Serin berangkat ke Johor dengan tujuan untuk mencari orang-orang yang ahli dalam urusan timah (Theo, 2014, p. 11). Wan Akub mendatangkan saudarasaudaranya dari Johor untuk ikut menambang di Muntok. Selain itu, ia juga mendatangkan para pekerja tambang timah dari Siam dan China.

Berkat upaya tersebut, hasi tambang timah bertambah dengan pesat. Muntok menjadi semakin ramai dan juga menjadi lebih Makmur atas usaha Wan Akub. Dengan demikian, dapat dikatakan bahwa selama pengurusan timah dipercayakan kepada Encek Wan Akub, Muntok berkembang dengan pesat. Tidak hanya itu, penduduk Pulau Bangka pada masa itu juga hidup dalam kesejahteraan. Encek Wan Akub memiliki peranan yang besar tidak hanya bagi Muntok tetapi juga bagi penduduk Pulau Bangka pada umumnya.

Meskipun demikian, terdapat juga masalah yang terjadi terutama dari kalangan keturunan Tionghoa. Orang-orang Cina memaksa untuk menguasai tambang timah di Bangka. Hal itu menyebabkan bentrokan antara orang Melayu dan Tionghoa. Akibat bentrokan tersebut, banyak korban berjatuhan dari kedua pihak, bahkan Wan Aqub yang turut melerai bentrokan pun ikut terluka parah. Bentrokan terhenti setelah orangorang Melayu berhasil mengalahkan orang-orang Cina. Meskipun dimenangkan oleh orang Melayu, namun Wan Akub dengan bijak tetap mengajak 
kedua belah pihak untuk bermusyawarah dalam rangka mendamaikan suasana.

Di sisi lain, seperti yang telah disebutkan bahwa sultan memerintahkan kepada Wan Akub untuk membangun benteng dari tanah liat dengan memakai jasa orang Bangka dengan upah yang wajar. Benteng tersebut berlokasi di Kampung Jiran Siantan atau yang sekarang dikenal dengan Kampung Tanjung di Muntok. Beberapa tahun kemudian, Wan Akub meninggal dunia. Wan Akub dimakamkan di perkuburan Kota Seribu di Muntok. Sampai saat ini, ia dikenal oleh masyarakat Muntok dengan panggilan Atok Akub.

Wan Akub masih dikenal oleh masyarakat Muntok. Salah satu bukti bahwa Wan Akub memiliki peranan dalam memajukan Muntok dapat dilihat dari generai yang jauh setelah Wan Akub ternyata masih mengenal sosoknya. Sosok Wan Akub bahkan diabadikan dalam sebuah kegiatan tahunan yang dikenal dengan "Turnamen Wan Akub Cup". Turnamen Wan Akub Cup diselenggarakan dalam rangka memperingati Hari Ulang Tahun (HUT) Muntok, sekaligus untuk mengenang tokoh Wan Akub (Dato' Rangga Setia Agama) (Riyadi, 2013).

Jika dilihat lebih dalam, ketokohan Wan Akub sejauh ini memiliki pengaruh yang signifikan di berbagai sisi, mulai dari politik, ekonomi, sosial, hingga budaya. Pengaruh ini tidak hanya di Muntok bahkan Bangka Belitung secara keseluruhan. Dari sisi politik, ketokohan Wan Akub di masa lalu telah menjadi semacam memori kolektif di kalangan masyarakat Muntok. Ketokohan Wan Akub telah menguatkan eksistensi popularitas orang Tionghoa di Muntok dari masa ke masa. Saat pemilihan calon legislatif, tidak jarang orang Melayu cukup percaya dengan ketokohan orang Tionghoa. Sebagai contoh adalah Basuki Tjahaja Purnama/Ahok baik di kancah perpolitikan daerah maupun nasional, serta Markus sebagai Bupati terpilih di Bangka Barat (Muntok). Dari sisi ekonomi, Wan Akub mampu memberikan pengetahuan jangka panjang mengenai pengelolaan timah. Masyarakat di seluruh daerah di Bangka Belitung sangat familiar dengan teknik yang dulu dikenalkan oleh Wan Akub. Sementara itu, dari sisi budaya, akulturasi budaya Tionghoa dan Melayu di Muntok terlihat sudah sangat mengakar. Terbukti dengan adanya produk kain cual yang sampai sekarang masih sangat dikenal sebagai produk hasil budaya Muntok. Dari sisi social, seperti yang telah dibahas di pendahuluan, ketokohan Wan Akub dalam memimpin Muntok memperkuat istilah thong ngin fan ngin jit jongyang cukup dikenal di Bangka. Hal ini lah yang menjadi citra Muntok sebagai Kota yang berbasis kerukunan antaretnis.

\section{Simpulan}

Berdasar pada penjelasan di atas, maka pembahasan tentang Peranan Wan Akub di Muntok Bangka pada Abad ke-18 dapat disimpulkan sebagai berikut. Latar belakang kedatangan Wan Akub di Kota Muntok melewati proses yang cukup panjang. Hal ini tidak terlepas juga dari peranan Sultan Mahmud Badaruddin Jayawikrama yang telah memberikan tanah Muntok kepada Wan akub. Tujuan diberikan tanah Muntok kepada Wan Akub tidak lain adalah agar Wan Akub dapat membangun wilayah Muntok, terutama karena wilayah Muntok memiliki potensi yang besar untuk dikembangkan menjadi basis pertambangan timah. Kehadiran Wan Akub di Muntok telah membawa banyak perubahan. Dapat dianalisis bahwa peranan Wan Akub atas Kota Muntok sangat beragam, di antaranya: membuka sistem irigasi/parit untuk membantu proses penambangan timah di Muntok; mendatangkan penambang timah dari luar Muntok; membangun benteng tanah liat untuk meredam pertikaian antaretnis di Muntok; menghadirkan peraturan timah tiban; serta menetapkan pembagian hasil timah sebagai bentuk balas jasa kepada Wan Akub dan kerabatnya, karena telah mengajarkan teknik pertambangan yang baru di Muntok. Terakhir, perpindahan kerabat Wan Akub dari Siantan ke Muntok juga meninggalkan keterampilan baru bagi masyarakat Muntok tentang tata cara menenun kain yang disebut cual. Berbagai kebijakan di atas pada akhirnya berpengaruh pada bidang ekonomi, politik, social, dan budaya di Muntok.

\section{Referensi}

Abdurrahman, D. (2010). Metodologi penelitian sejarah. Jakarta: Bina Aksara.

Dediarman (2019). Gelar Abang dan Yang di Kampung Muntok, Daik Lingga. Diakses pada 23 Juli, 2020, dari 
https://kebudayaan.kemdikbud.go.id/b pnbkepri/gelar-abang-dan-yang-dikampung-mentok-daik-lingga/.

Derks, H. (2012). Tin for opium, opium for tin? In History of the opium problem: The assault on the east, ca. 1600-1950 (pp. 295-306). Leiden \& Boston: Brill. doi:10.1163/j.ctv4cbhdf.22

Direktorat Jenderal Nilai Budaya, Seni, dan Film Departemen Kebudayaan dan Pariwisata. (2009). Kain Cual Bangka. Jakarta:

Departemen Kebudayaan dan Pariwisata.

Ellisa, E. 2013. The emergence of small-scale tourism of the Mining City of Mentok, Indonesia. Makalah dipresentasikan pada Seminar Internasional the Past for Sale? The Economic Entanglements of Cultural Heritage, May 15-17, 2013. Massachusetts: University of Massachusetts Amherst campus, USA.

Gottschalk, Louis (Ed.). 2008. Mengerti sejarah. Jakarta: Universitas Indonesia.

Hanafiah, D. (2009). Muntok kota khusus/istimewa Kesultanan Palembang Darussalam: Latar belakang sejarah berdirinya Kota Muntok. Makalah dalam Seminar Hari Berdirinya Kota Muntok, Pemerintah Kabupaten.

Heidhues, M. F. S. (2008). Timah Bangka dan Lada Mentok: peran masyarakat Tionghoa dalam pembangunan Pulau Bangka Abad $X V I I I$ s / $d X X$. Jakarta: Yayasan Nabil.

Ibrahim (2007). Koba dalam historiografi: sebuah penelusuran jejak sejarah Koba. Yogyakarta: Penerbitan Filsafat UGM.

Idi, Abdullah (2011). Bangka: Sejarah sosial CinaMelayu. Yogyakarta: Tiara Wacana.

Isa, Syarifuddin (t. t.). Sejarah Muntok. Bangka: (Tidak diterbitkan).

Kurniawan, K. R. et al. (2017). Shared urban heritage: Traces of Sino-Moslem Malay descendants from Johor in Mento-Bangka. IWUPCD 2017: 18th-22nd September 2017.

Novita, Aryandini (2017). Pemukiman orang Melayu di Bangka. Siddhayatra, 22. http://siddhayatra.kemdikbud.go.id/inde x.php/siddhayatra/article/view/61/30

Riyadi (2013). Warga Muntok gelar turnamen Encek Wan Akub. Diakses pada 20 Januari, 2020, dari https://bangka.tribunnews.com/2013/09 /03/warga-muntok-gelar-turnamenencek-wan-akub.

Ross, C. (2014). The Tin Frontier: Mining, Empire, and Environment in Southeast Asia, 1870s-1930s. Environmental History, 19(3), 454-479. Retrieved January 3, 2021, from http://www.jstor.org/stable/24690599

Sari, F. (2015). Sistem kekerabatan sosial masyarakat dalam penggunaan gelar kebangsawanan "Yang" dan "Abang” Di Kota Muntok Kepulauan Bangka (17341816). Jurnal Cikestra, 4, (8).

Siburian, R. \& Haba, J. (2016). Konservasi mangrove dan kesejahteraan masyarakat. Jakarta: Pustaka Obor Indonesia

Sujitno, S. (2011). Legenda dalam sejarah Bangka. Jakarta Selatan: Cempaka Publishing.

Theo, Rika \& Fennie L. (2014). Kisah kultur dan tradisi Tionghoa Bangka. Jakarta: Kompas.

van Wyhe, J., \& Drawhorn, G. (2015). 'I am Ali Wallace': The Malay Assistant of Alfred Russel Wallace. Journal of the Malaysian Branch of the Royal Asiatic Society, 88(1 (308)), 3-31. doi:10.2307/26527691

Yuliarni (2015). Partisipasi politik etnis Tionghoa di Bangka pada masa Orde Baru dan Reformasi (1967-2009)(Tesis). Jurusan Ilmu Sejarah, Universitas Andalas, Padang, Indonesia.

Yusuf, L. M. (2013). Ziarah makam Kute Seribu. Diakses pada 20 Januari, 2020 dari http://portal.bangkabaratkab.go.id/conte nt/ziarah-makam-kute-seribu. 